\title{
Analysis of self-trapped hole mobility in alkali halides and metal halides
}

\author{
A.I. $\operatorname{Popov}^{1 *}$, E.A. Kotomin ${ }^{1,2}$, J. Maier ${ }^{2}$ \\ ${ }^{1}$ Institute of Solid State Physics, University of Latvia, 8 Kengaraga, LV-1063 Riga, \\ Latvia \\ ${ }^{2}$ Max Planck Institute for Solid State Research, Heisenbergstr. 1, Stuttgart, Germany \\ *popov@latnet.lv
}

\begin{abstract}
The small radius hole polarons (self-trapped holes (STH) known also as the $V_{k}$ centres) are very common color centers observed in alkali halides and alkaline-earth halides. Their mobility controls the rate of secondary reactions between electron and hole defects and thus radiation stability/sensitivity of materials. We have analysed here the correlation between the temperatures at which hole polarons start migration in a series of alkali halides (fluorites, chlorides, bromides, iodides) and the lattice displacement around $\mathrm{X}_{2}{ }^{-}$quasi-molecule. These results are especially important for identification of the selftrapped holes, for example, in novel scintillating materials such as $\mathrm{SrI}_{2}$, as well as in a large family of perovskite halides and more complex halide materials.
\end{abstract}

\section{Introduction}

The mobilities of small radius polarons affect properties of many insulating materials and thus attract considerable attention [1-3]. The self-trapped hole (STH) polarons (called $V_{k}$ centres), in which a hole is shared by two nearest halogen ions, $\mathrm{X}_{2}^{-}$, are very common color centers created in alkali halides, alkaline-earth halides and some other halides under various kinds of irradiation (UV light, electrons, gamma rays, neutrons, heavy swift ions) [4-28] Their mobility controls the rate of secondary reactions between electron and hole defects and thus radiation stability/sensitivity of materials.

The hole polarons start to migrate and recombine above certain onset temperatures (in the range 50-200 K). Their diffusion-controlled decay has been observed by different experimental techniques in almost all alkali halides, as well as in some other binary halides, but also in complex halides, such as perovskite halides, ammonium halides, halide sodalites etc. $[8,11,12,15,23,25,26]$

In this paper, we review and analyse the STH migration temperatures for a series of alkali halides as a function of halogen-halogen $(\mathrm{X}-\mathrm{X})$ distance in a regular crystalline lattice as well as the bond length in isolated $\mathrm{X}_{2}^{-}$molecular ions. 


\section{Analysis of the STH migration}

Due to formation of chemical bond, the equilibrium distance of a $\mathrm{X}_{2}^{-}$hole polaron is smaller than the distance between two nearest host halogens in perfect crystals and very close to that in a gas-phase molecule [29] (Fig. 1). Above certain temperatures the STH migration occurs via a quasi-molecule reorientation by $60^{\circ}$ or $90^{\circ}$ (dependent on the fc.c. or b.c.c. lattice), during which one of the two halogens becomes a common partner in the old and new quasi-molecule (bond switching). Application of the small radius polaron theory to the $\mathrm{V}_{\mathrm{k}}$ centers [30] has shown that its hopping probability $\mathrm{W}$ is expected to be an exponential function of the migration energy $E_{a}$

$$
\begin{gathered}
\mathrm{W}=v_{0} \exp \left(-\mathrm{E}_{\mathrm{a}} / \mathrm{kT}\right), \\
\mathrm{E}_{\mathrm{a}}=\mathrm{S} \mathrm{h} \omega / 4, \quad \mathrm{~S}=\mathrm{A} \mathrm{M} \omega \Delta^{2},
\end{gathered}
$$

where $v_{0}$ is a pre-factor, $\mathrm{S}$ the so-called Huang-Rhys factor, dependent on the displacement $\Delta$ of the halogen from the regular lattice site after formation of the chemical bond (Fig. 1), $\omega$ is the LO optical phonon frequency, M the halogen mass, and A prefactor depending on the reorientation angle $\left(A=0.9\right.$ for $\left.60^{\circ}\right)$. The hole delocalization/reorientation occurs when during thermal fluctuations one of halogens in the STH approaches the regular lattice site. Eqs. (1), (2) show that a decrease of displacement $\Delta$ lowers the migration energy and hence the onset temperature $T_{\text {migr }}$ at which hole migration begins. The latter may be defined by the temperature at which STH performs one jump per second, $\mathrm{W}=1 \mathrm{~s}^{-1}$

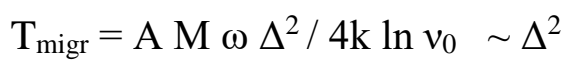

i.e. is a quadratic function of the ionic displacement.

Tables 1 to 4 summarize the experimental migration temperatures and inter-halogen distances for different types of crystalline structures - f.c.c., b.c.c., fluorite, and some more complicated structures (wurtzite, layered maltlockite etc) corresponding to four classes of halides - fluorites, chlorides, bromides, and iodides. These literature data are used for analysing the dependence of the migration temperatures on the halogen-halogen distances in the above-mentioned four classes of halogen-containing solids (Figs. 2-5).

As one can see, the migration temperatures show a linear dependence on the displacement $\Delta$, rather than the theoretically predicted quadratic one. (The first point with 
0K corresponds to the equilibrium distances in free $\mathrm{X}_{2}^{-}$molecules.) The reason for this is not clear at the moment. What is more striking is that this linear dependence holds for each class, e.g. fluorides, irrespective on the specific lattice structure, e.g. f.c.c. LiF, fluorite $\mathrm{CaF}_{2}$, perovskite $\mathrm{KMgF}_{3}$. This observation clearly demonstrates that the main factor determining the migration temperature is the lattice displacement.

These results may be useful in the following cases:

1. Very often thermoluminescence peaks or optical absorption annealing stages are attributed to the self-trapped holes, but it remains unclear, whether it is captured by impurities or self-trapped in a regular lattice. This linear relationship certainly helps to make a more specific conclusion.

2. For STH in complex structures with several halogen-halogen distances, the linear law allows us to estimate the range of lattice sites where the STH could exist. For example, in there are 12 symmetrically distinct I-I ion pairs a novel efficient scintillator $\mathrm{SrI}_{2}$ [31-33], with a broad range of the distances, 3.9-5.0 $\AA$ [32]. From our analysis for the iodides (Fig.5), we expect that migration temperatures of $\mathrm{V}_{\mathrm{k}}$ centers in $\mathrm{SrI}_{2}$ fall into range 50 $100 \mathrm{~K}$, respectively. Indeed, Yang et al [33] have recently reported thermoluminescence of X-rayed $\mathrm{SrI}_{2}$ :Eu consisting of 9 peaks, between LHeT and RT, including three peaks below $100 \mathrm{~K}$. It is important, however, that the peak at $50 \mathrm{~K}$ dominates the thermoluminescence glow curve, which is more than an order of magnitude stronger than any other peak, which is typical for Vk centers in ionic solids. The position of this peak corresponds to the lowest distance among all $\mathrm{I}-\mathrm{I}$ pairs where the $\mathrm{V}_{\mathrm{k}}$ center could be localized.

This analysis indicates how to interpret the thermoluminescence peaks in this and similar complex materials, but also allows conclusions about stable local atomic configurations, in terms of the carrier self-trapping. Moreover, it allows us to understand how to use impurity doping of the material for controling the channels of the electronic excitation relaxation.

Another example of complex materials is the family of metal fluorohalides, which are important media for $\mathrm{X}$-ray and neutron imaging [35-38]. In $\mathrm{BaFCl}$ layered matlockite crystals, only $\mathrm{Cl}_{2}{ }^{-}$in-plane configuration was found (see Table 4). Simple analysis of Fig.3 allows one to conclude that $V_{k}$ in-plane configuration with $T_{\text {mig }} \sim 130 \mathrm{~K}$ [35] fits well the proposed linear relation, and to predict that the $V_{k}$ migration for out-of-plane configuration (with the distance of 2.72 A close to $2.71 \AA$ in free molecule) could begin at very low temperatures. This is why such Vk centers have not been observed in 
commonly used experiments performed above LHeT. We suggest that only experiments at temperatures below LHeT could help to observe this type of defects.

From the viewpoint of scintillator engineering, materials are required with fast hole diffusion (and thus recombination) at room temperatures, which holds for STH with small lattice displacements and thus low delocalization temperatures, e.g. NaI.

3. It is established that $\mathrm{V}_{\mathrm{k}}$ centers are produced and well studied in all fluoroperovskites $\left(\mathrm{KMgF}_{3}\right.$ (Fig. 2), $\left.\mathrm{BaLiF}_{3}, \mathrm{KZnF}_{3}\right)$. We have demonstrated here that their thermal stability/ migration follow the same pattern as simple binary halides. This makes it possible to straightforwardly assess the thermal stability of the STH for a wide range of $\mathrm{AMX}_{3}$ materials. In forthcoming paper we plan to discuss the behavior of $\mathrm{V}_{\mathrm{k}}$ centers in more details.

\section{Conclusions}

A simple linear dependence of the migration temperatures of self-trapped holes in several classes of ionic solids was established as a function of the two halogen atom relaxation constituting the $\mathrm{X}_{2}^{-}$quasi-molecule from the regular lattice sites. As demonstrated in the paper, this correlation allows us to identify the STH and their structural configuration in various cases, including the promising scintillating material $\mathrm{SrI}_{2}$.

\section{Acknowledgments}

Support from Latvian National Research Program IMIS2 (2014-2017) and LZP Grant No. 237/2012 (2013-2016) is greatly appreciated.

\section{References}

[1] A.S. Alexandrov, N.F. Mott, Polarons and Bipolarons (Singapore: World Scientific, 1995)

[2] A.M. Stoneham, J. Gavartin, A.L. Shluger et al, J. Phys.: Cond. Matt., 19 (2007) 255208

[3] D. Emin, Physical Review B 48 (1993) 13691

[4] T.G. Castner, W. Känzig, Journal of Physics and Chemistry of Solids, 3 (1957) 178195.

[5] C.J. Delbecq, W.Hayes, P. H. Yuster, P. H. Physical Review, 121(1961) 1043.

[6] F.J. Keller, R.B Murray, Physical Review, 150 (1966) 670.

[7] A.N. Jette, T.L. Gilbert, T.P. Das, Phys. Rev., 184 (1969), p. 884 
[8] C.J. Delbecq, Y. Toyozawa, P.H. Yuster, P. H. Physical Review B, 9 (1970) 4497.

[9] D. Schoemaker, Physical Review B 7 (1973) 786.

[10] R. Monnier, K.S. Song, A.M. Stoneham, Journal of Physics C: Solid State Physics, 10 (1977) 4441

[11] E. Kotomin, I. Tale, V. Tale, P. Butlers, P. Kulis, J. Phys.: Condens. Matter, 1 (1989), pp. 6777-6785

[12] U. Rogulis, E. Kotomin, Radiation Effects and Defects in Solids, 111(1989), 191205.

[13] E.A. Kotomin, A.I. Popov, R.I. Eglitis, R. I. Journal of Physics: Condensed Matter, 4 (1992), 5901.

[14] T. Suzuki, K. Tanimura, N. Itoh, Physical Review B, 48 (1993) 9298.

[15] Z. Postawa, J. Kolodziej, G. Baran, P. Czuba, P. Piatkowski, M. Szymonski, I.Plavina, A. Popov, Nucl. Instrum. Methods B, 100 (1995), 228-231.

[16] U. Rogulis, C. Dietze, T.Pawlik, T.Hangleiter, J.M. Spaeth, Journal of applied physics, 80 (1996) 2430-2435.

[17] U. Rogulis, S. Schweizer, S. Assmann, J.M. Spaeth, Journal of applied physics, 84 (1998) 4537-4542.

[18] S.A. Chernov, L. Trinkler, A.I. Popov. Radiation effects and defects in solids, 143 (1998), 345-355.

[19] A.I. Popov, S.A. Chernov, L.E. Trinkler, Nucl. Instrum. Methods B, 122 (1997) 602-605.

[20] M. Kirm, A. Lushchik, C. Lushchik, I. Martinson, V. Nagirnyi, E. Vasil'chenko,. Journal of Physics: Condensed Matter, 10 (1998) 3509.

[21] A.I. Popov, E. Balanzat, Nucl. Instrum. Methods B, 166 (2000) 545-549.

[ 22] A. Lushchik, C. Lushchik, M. Kirm, V. Nagirnyi, F. Savikhin, E. Vasil'chenko, Nucl. Instrum. Methods B, 250 (2006), 330-336.

[23] F. W. Patten, M.J. Marrone, Physical Review 142 (1966) 513.

[24] T.P.P. Hall, Br. J. Appl. Phys., 17 (1966), pp. 1011-1018

[25] L.E. Halliburton, E. Sonder, Solid State Commun., 21 (1977), pp. 445-447

[26] I. Tale, H.-J. Fitting, P. Kulis, V. Ogorodnik, U. Rogulis, M. Springis, V. Tale, J.

Trokss, A. Veispals, Radiat. Eff. Def. Solids, 149 (1999), pp. 269-272

[27] C.L. Marquardt, The Journal of Chemical Physics, 48 (1968), 994-996. 
[28] F.J. López, A. Martín, Physical Review B, 38(1988), 6392.

[29] P. Cade, A.M. Stoneham, P.W. Tasker, Phys Rev B 30 (1984) 4621.

[30] K.S. Song. J. Phys. Chem. Sol. 31 (1970) 1389.

[31] V. Pankratov, A. I. Popov, L. Shirmane, A. Kotlov, G. A. Bizarri, A. Burger, R.T. Williams, Radiation Measurements, 56 (20130 13-17.

[32] F. Zhou, B. Sadigh, P. Erhart, D. Aberg. NPJ Computational Materials 2 (2016) 16022

[33] K. Yang, M. Zhuravleva, C.L. Melcher. J. Lumin., 132 (2012) 1824-1829.

[34] R. C. Baetzold, Physical Review B, 36(1987) 9182.

[35] M. Yuste, L. Taurel, M. Rahmani, Solid State Communications, 17 (1975) 14351438.

[36] S. Schweizer, J.M. Spaeth, T.J. Bastow, Journal of Physics: Condensed Matter, 10 (1998) 9111.

[37] S. Schweizer, physica status solidi (a), 187 (2001), 335-393.

[38] A.I. Popov, J. Zimmermann, G.J. McIntyre, C. Wilkinson, Optical Materials 59 (2016) 83-86. 
Table 1. Compilation of migration temperature of Vk centers in some metal halides, obtained via thermal annealing of optical absorption, EPR as well as TSL measurements. Alkali halides with NaCl-type lattice $\mathrm{Cl}-\mathrm{Cl}$ distance $=\mathrm{a} / \sqrt{2}=0.707 \mathrm{a}$, $\mathrm{a}$ is the $\mathrm{Me}-\mathrm{X}$ distance.

\begin{tabular}{|l|l|l|l|l|}
\hline Material & Type & $\begin{array}{l}\text { Lattice } \\
\text { constant }\end{array}$ & $\begin{array}{l}\text { Halogen- } \\
\text { halogen } \\
\text { distance }\end{array}$ & $\mathrm{T}_{\text {migr }}\left(\mathrm{V}_{\mathrm{k}}\right)$ \\
\hline $\mathrm{LiF}$ & $\mathrm{NaCl}$ & 4.028 & 2.8482 & $125 ; 150$ \\
\hline $\mathrm{NaF}$ & $\mathrm{NaCl}$ & 4.634 & 3.2767 & $160 ; 180$ \\
\hline $\mathrm{KF}$ & $\mathrm{NaCl}$ & 5.348 & 3.7816 & $175 ; 210$ \\
\hline $\mathrm{RbF}$ & $\mathrm{NaCl}$ & 5.63 & 3.9810 & 216 \\
\hline \multicolumn{1}{|c|}{$\mathrm{F}_{2}^{-}$} & & & 1.90 & \\
\hline $\mathrm{LiCl}$ & $\mathrm{NaCl}$ & 5.14 & 3.6345 & $115,120,123$ \\
\hline $\mathrm{NaCl}$ & $\mathrm{NaCl}$ & 5.64 & 3.9881 & $150 ; 165 ; 168$ \\
\hline $\mathrm{KCl}$ & $\mathrm{NaCl}$ & 6.294 & 4.4505 & $205 ; 208 ; 210$ \\
\hline $\mathrm{RbCl}$ & $\mathrm{NaCl}$ & 6.582 & 4.6542 & $220 ; 240$ \\
\hline \multicolumn{1}{c|}{$\mathrm{Cl}_{2}^{-}$} & & & 2.71 & \\
\hline $\mathrm{LiBr}$ & $\mathrm{NaCl}$ & 5.502 & 3.8905 & 122 \\
\hline $\mathrm{NaBr}$ & $\mathrm{NaCl}$ & 5.978 & 4.2271 & $115 ; 134$ \\
\hline $\mathrm{KBr}$ & $\mathrm{NaCl}$ & 6.596 & 4.6641 & $160 ; 170 ; 175$ \\
\hline $\mathrm{RbBr}$ & $\mathrm{NaCl}$ & 6.89 & 4.8720 & $170 ; 206$ \\
\hline \multicolumn{1}{|c|}{$\mathrm{Br}_{2}^{-}$} & & & 2.90 & \\
\hline $\mathrm{LiI}$ & $\mathrm{NaCl}$ & 6.00 & 4.2426 & \\
\hline $\mathrm{NaI}$ & $\mathrm{NaCl}$ & 6.474 & 4.5778 & $58 ; 60$ \\
\hline $\mathrm{KI}$ & $\mathrm{NaCl}$ & 7.066 & 4.9964 & $105 ; 110$ \\
\hline $\mathrm{RbI}$ & $\mathrm{NaCl}$ & 7.342 & 5.192 & 125 \\
\hline & & & 3.28 & \\
\hline
\end{tabular}

Table 2. The same as Table 1 for alkali halides with $\mathrm{CsCl}$-type lattice, $\mathrm{Cl}-\mathrm{Cl}$ distance $=\mathrm{a}$

\begin{tabular}{|c|c|c|c|c|}
\hline Material & Type & $\begin{array}{l}\text { Lattice } \\
\text { constant }\end{array}$ & $\begin{array}{l}\text { Halogen- } \\
\text { halogen } \\
\text { distance }\end{array}$ & $\mathrm{T}_{\text {migr }}\left(\mathrm{V}_{\mathrm{k}}\right)$ \\
\hline $\mathrm{CsCl}$ & $\mathrm{CsCl}$ & 4.123 & 4.123 & 202 \\
\hline $\mathrm{CsBr}$ & $\mathrm{CsCl}$ & 4.286 & 4.286 & $122 ; 130$ \\
\hline CsI & $\mathrm{CsCl}$ & 4.5667 & 4.5667 & $\begin{array}{l}60 \text { (linear); } 85 \\
\text { (jump) }\end{array}$ \\
\hline $\mathrm{NH}_{4} \mathrm{Cl}$ & $\mathrm{CsCl}$ & 3.8756 & 3.8756 & 180 \\
\hline $\mathrm{NH}_{4} \mathrm{Br}$ & $\mathrm{CsCl}$ & 4.0594 & 4.0594 & 120 \\
\hline $\mathrm{TlCl}$ & $\mathrm{CsCl}$ & 3.8340 & 3.8340 & Not found \\
\hline $\mathrm{TlBr}$ & $\mathrm{CsCl}$ & 3.97 & 3.97 & Not found \\
\hline TII & $\mathrm{CsCl}$ & 4.108 & 4.108 & Not found \\
\hline
\end{tabular}


Table 3. The same as table 1 for metal halides with fluorite lattice, F-F distance = $\mathrm{a} / 2=0.5 \mathrm{a}$

\begin{tabular}{|l|l|l|l|l|}
\hline Material & Type & $\begin{array}{l}\text { Lattice } \\
\text { constant }\end{array}$ & $\begin{array}{l}\text { Halogen- } \\
\text { halogen } \\
\text { distance }\end{array}$ & Tmigr $\left(\mathrm{V}_{\mathrm{k}}\right)$ \\
\hline $\mathrm{CaF}_{2}$ & $\mathrm{CaF}_{2}$ & 5.4626 & 2.7313 & $126 \mathrm{~K}$ \\
\hline $\mathrm{SrF} 2$ & $\mathrm{CaF}_{2}$ & 5.800 & 2.900 & $110 ; 120$ \\
\hline $\mathrm{SrCl}_{2}$ & $\mathrm{CaF}_{2}$ & 6.9767 & 3.488 & 105 \\
\hline $\mathrm{CdF}_{2}$ & $\mathrm{CaF}_{2}$ & 5.3895 & 2.695 & 95 \\
\hline
\end{tabular}

Table 4. The same as Table 1 for several other halides with crystalline structures different from those in Tables 1-3.

\begin{tabular}{|l|l|l|l|l|}
\hline Material & Type & $\begin{array}{l}\text { Lattice } \\
\text { constant }\end{array}$ & $\begin{array}{l}\text { Halogen- } \\
\text { halogen } \\
\text { distance }\end{array}$ & $\mathrm{T}_{\text {migr }}\left(\mathrm{V}_{\mathrm{k}}\right)$ \\
\hline $\mathrm{AgI}$ & wurtzite & $\mathrm{a}=4.580 ; \mathrm{c}=7.494$ & $\mathrm{a}=4.580$ & Not found \\
\hline $\mathrm{NH}_{4} \mathrm{~F}$ & wurtzite & $\mathrm{a}=4.390 ; \mathrm{c}=7.02$ & $\mathrm{a}=4.390$ & Not found \\
\hline $\mathrm{KMgF}_{3}$ & perovskite & $\mathrm{a}=3.93$ & $\begin{array}{l}\mathrm{a} / \sqrt{2}=0.707 \mathrm{a}= \\
2.78\end{array}$ & 110 \\
\hline $\mathrm{BaFCl}$ (only $_{\left.\mathrm{Cl}_{2}{ }^{-}\right)}$ & layered & & $\begin{array}{l}4.11 \text { (in-plane) } \\
2.72 \text { (out- } \\
\text { of_plane) }\end{array}$ & 130 \\
\hline
\end{tabular}


Fig.1. Schematic view of the STH in f.c.c. structure, $\Delta$ is halogen displacement from the perfect lattice site as a result of the STH formation

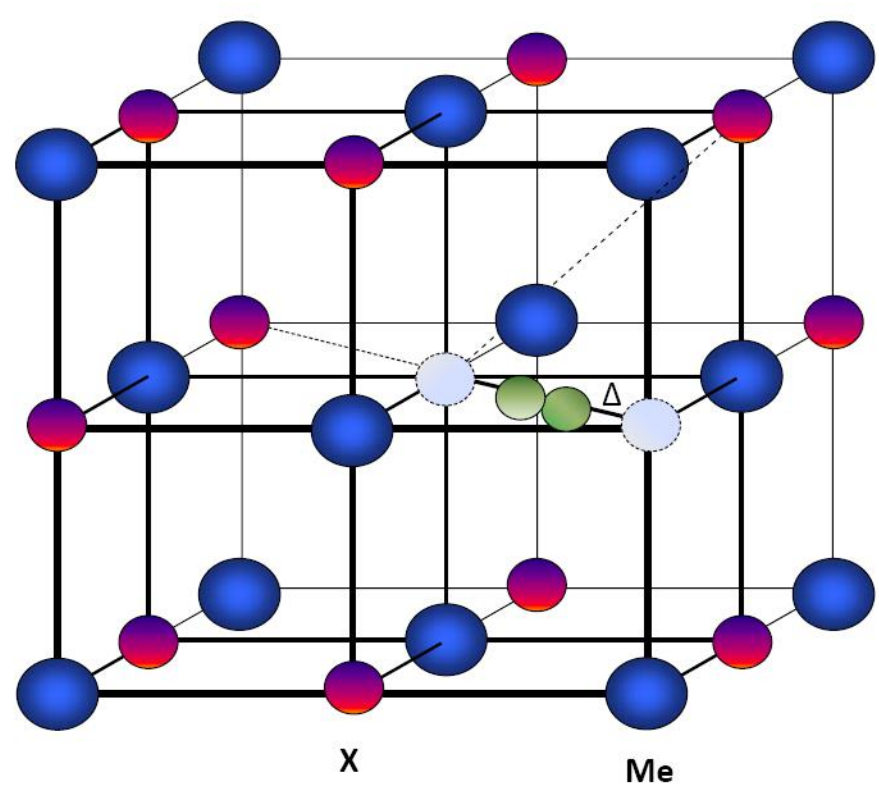

Fig. 2. Dependence of the STH delocalization and migration temperature for a series of fluorides as a function of halogen-halogen distances in the perfect crystal (see table 1)

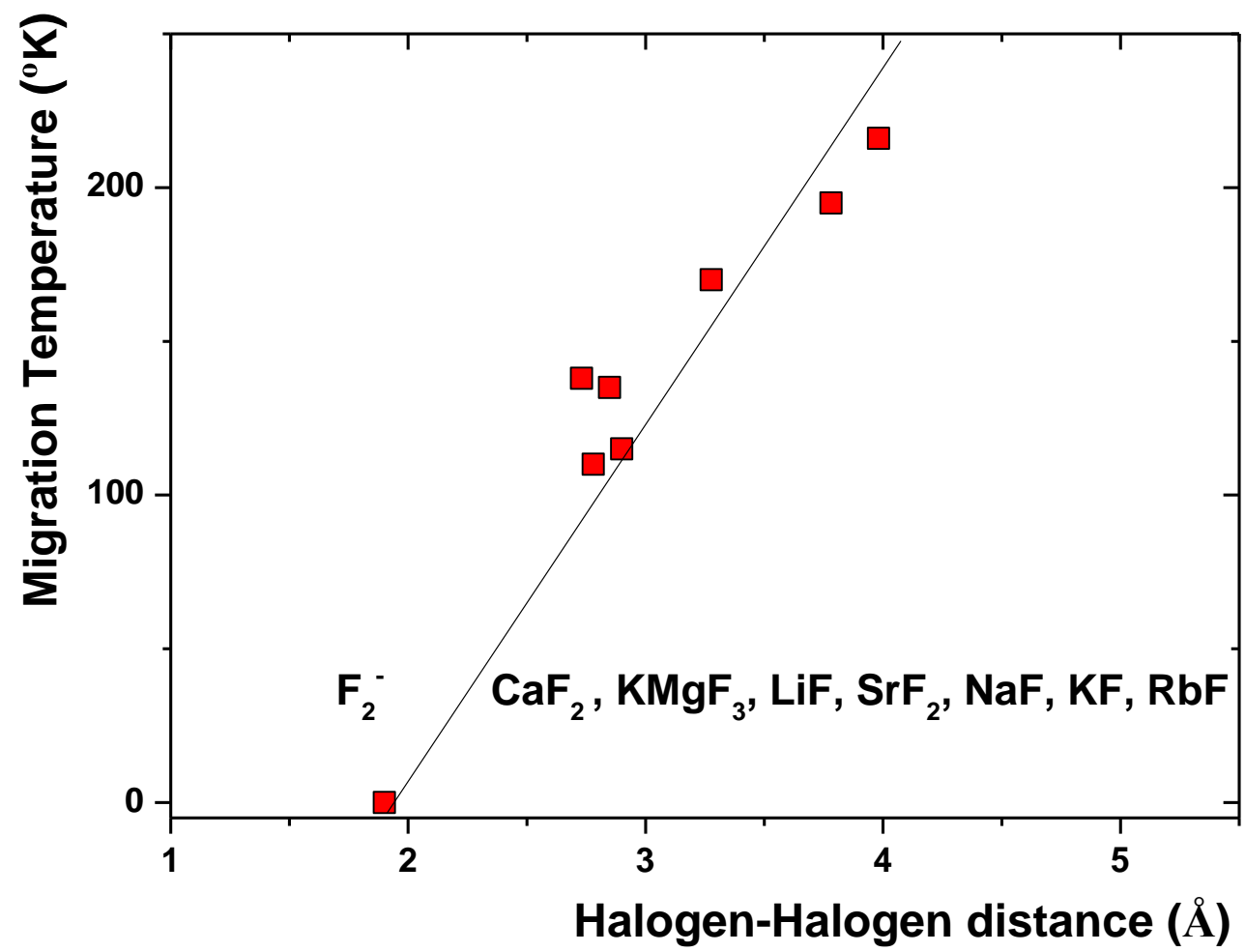


Fig.3. The same as Fig.2 for chlorides,

Fig.4. The same as Fig. 1 for bromides
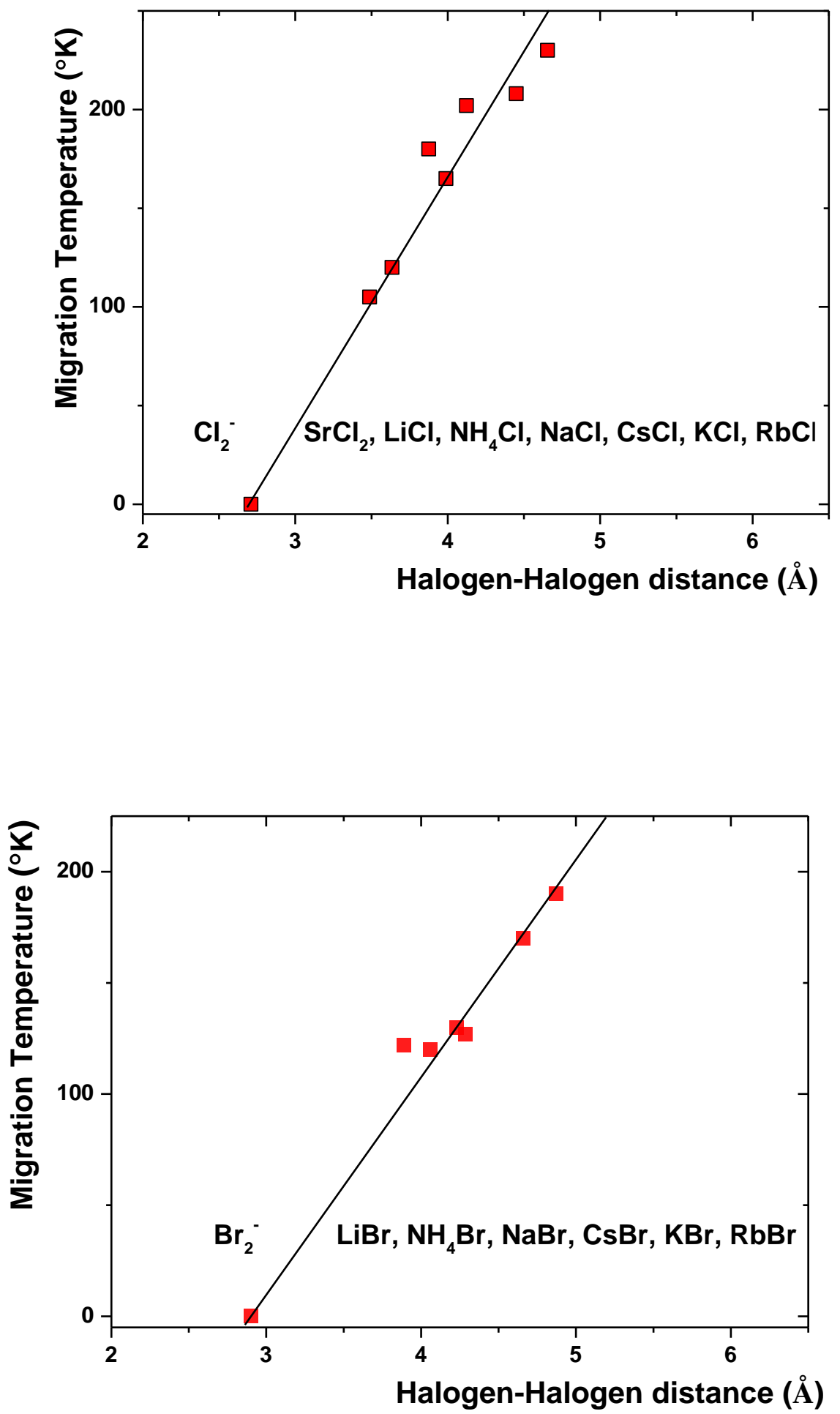
Fig.5. The same as Fig. 1 for iodides

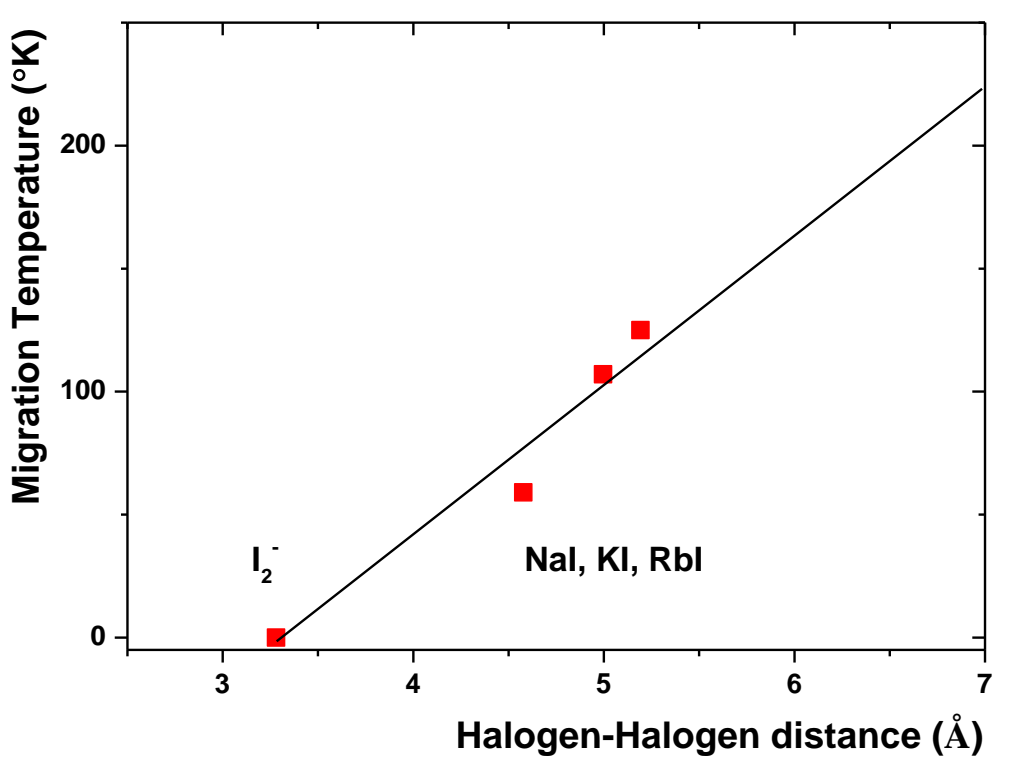

